\title{
Changing People, Changing Lives Through Public Participation and Social Transformation: A South African Case Study of a Rural Development Programme
}

\section{Allan Roman \& Greg Ruiters}

To cite this article: Allan Roman \& Greg Ruiters (2020) Changing People, Changing Lives Through Public Participation and Social Transformation: A South African Case Study of a Rural Development Programme, Politikon, 47:2, 253-268, DOI: 10.1080/02589346.2019.1697533

To link to this article: https://doi.org/10.1080/02589346.2019.1697533

\section{曲 Published online: 05 Dec 2019.}

\section{Submit your article to this journal $\widetilde{ }$}

Џ Article views: 281

Q View related articles ¿ 


\title{
Changing People, Changing Lives Through Public Participation and Social Transformation: A South African Case Study of a Rural Development Programme
}

\author{
Allan Roman and Greg Ruiters \\ The School of Government, University of the Western Cape, Cape Town, South Africa
}

\begin{abstract}
During 2009, in what seemed to be a return to RDP-style thinking, the Comprehensive Rural Development Programme (CRDP) was adopted nationally to tackle not only underdevelopment, poverty, unemployment, and other social ills, but also to enable 'rural people to take control of their destiny' with the support of 'well-structured community organisations' called Council of Stakeholders (CoS). Most existing studies, however, tend to devalue the CRDP, describing it as ill-conceived. This study investigated three Western Cape wards in South Africa, finding that both governmental and non-governmental actors had a less negative view and were actively trying to pursue a new form of co-operation. It is the only programme that attempts to be truly intergovernmental and community-based. The study's results suggest that the CRDP can contribute to a deep process of change and empowerment. This change, in turn, could contribute to desired larger-scale changes and concerted collective action to drive development in locally appropriate ways.
\end{abstract}

\section{Background and introduction}

The mandate of the national Department of Rural Development and Land Reform (DRDLR) is to develop rural areas throughout South Africa. To achieve this, the Department has implemented many multifaceted programmes and more recently in 2009, the Comprehensive Rural Development Programme (CRDP). The CRDP, announced after the 2007 Polokwane ANC conference and ushered in by the Zuma presidency in 2009, is geographically targeted at specific poor wards. Residents in such wards (or nodes) were called upon by government to form representative community structures called the Council of Stakeholders (CoS). Moreover, all relevant government departments (provincial and national) and local authorities were meant to focus on and co-ordinate efforts to assist such wards.

Since 2010, the Western Cape Government, through the Western Cape Department of Agriculture (WCDoA), developed its own Rural Development Model (RDM) to promote a 'well-structured and organised community' in 16 of the poorest rural areas in the province to address, amongst others, poverty, food insecurity, unemployment, and the lack of basic services. The RDM aims are aligned to the CRDP, which include the need to reduce local and regional disparities and 'to ensure meaningful community participation, leadership, and ownership in change efforts' (WCDoA 2011). In the Western Cape (WC), the Rural Development (Programme 8) was initiated at the beginning of February 2010 after the appointment of a Chief Director: Rural Development. The key policy priority of the Programme is to create an enabling environment that will facilitate private sector investment 
and socio-economic development in rural areas. The programme Rural Development is structured into three sub-programmes: Development Coordination, Social Facilitation and Farm Worker Development (WC Rural Development Model updated n.d.).

Government support for the CoS and its projects was meant to last three years and incorporated a programme logic based on three sequential phases. It started with the establishment of an Interdepartmental Steering Committee (ISC) made up of several provincial departments, the national department (DRDLR 2012b) and local government, followed by a social facilitation process resulting in the Councils of Stakeholders (CoS) being formed. The third phase comprises community participation sessions, where through the CoS the community prioritises potential projects. More importantly, it was envisaged that the CRDP should follow a 'bottom up' approach with the community providing a popular base to ensure that 'real needs' are addressed. Since the CRDP is a 'joint project between the three spheres of government, financial contributions will be made by all departments involved depending on the nature of the projects identified during the social facilitation, social upliftment, infrastructure development and economic development phases' (WCDoA 2011).

This article evaluates community participation and community building processes in the three different Councils of Stakeholders (CoS) to achieve the desired outcomes of the Rural Development Model. The CoS's criteria of success or failure according to the department (WCDoA 2011) were that the model would mean making better decisions, via community (public) participation in the CoS; reducing inefficiencies; establishing and maintaining sound governance; increasing community ownership, and a more responsive and accountable government.

\section{Debates on rural development and community participation}

The importance of peri-urban and rural areas in South Africa cannot be overstated especially in the light of three recent factors: calls for land to be returned to its 'rightful owners' (without compensation) and for a more equitable distribution of land; secondly, the persistent failure of previous rural development efforts (Cousins and Walker 2015) and thirdly, renewed land grabs by powerfully organised black political elites (Tapscott 2017; Hall 2019). As Hall (2019) found 'politically connected individual and companies are getting lucrative contracts from the state to take over land reforms with subsidies that should be directed to impoverished rural farm-dwellers and emerging commercial farmers'. Cousins (2016) argues the CRDP is a short term, training based intervention that is based on micro-projects and only provides short term employment. He called it an 'expensive and ineffective distraction. The coordination of developmental investment in rural areas should be left to local government bodies' (Cousins 2016, 18).

But there is also a problem with sweeping rejections of all government-led rural development and community mobilisation efforts (Cousins and Walker 2015; Hall 2015). We argue that what is needed is a more finely grained analysis which can pick through details and complexities of what exactly happens with government-sponsored rural development projects - hence the case studies. Even if projects failed in their initial intended outcomes, there are many unintended outcomes that may sometimes have positive side effects related to the agency of residents in these wards.

According to the international literature, community participation and bottom-up approaches to rural development are believed to produce better decisions because 
such decisions are made with, by and for a particular community. Moreover, it is expected that decisions will be context-appropriate and tailored to the specific needs of that community (Francis and James 2003; Agossou and Ayres 2000; Dasgupta and Beard 2007). Appropriate decisions might also reduce waste incurred in the rollingout of unnecessary or inappropriate programmes. Secondly, participation increases community ownership over decisions made, because the community has played a role in influencing those decisions, and thus they are more likely to be willing to bear the implications of these decisions (Buchy and Hoverman 2000). Thirdly, community participation is believed to reduce the inefficiencies of centralised bureaucracy, by decentralising the locus of decision-making to the people affected by the decisions, so that actions can be better targeted and be more efficient (Francis and James 2003; Irvin and Stansbury 2004; Dasgupta and Beard 2007; Buchy and Hoverman 2000). Lastly, participation may lead to a more accountable government, as civil society is empowered to demand an accountable government (Dasgupta and Beard 2007), as society's involvement means that the processes are more transparent (Francis and James 2003). Furthermore, public participation increases representation in the decision-making sphere, which can be seen as a benefit in itself (Kakumba 2010). Community participation can also be seen as a worthy end in itself. In fact, it is believed to bring about change through providing educational and democratic learning experiences for participants, thereby empowering an active and engaged citizenry (Irvin and Stansbury 2004). In addition, participation may have significant value at a relational level, promoting public trust in government, as well as improved relations in a community (Irvin and Stansbury 2004; Buchy and Hoverman 2000).

However, this overly positive view is an over-simplification. In the first place it makes a number of problematic assumptions about collective action: as Booth and Cammack (2013) argue; it is assumed that community actors are committed to collective action for the public good and that community stakeholders have the time, capacity and resources to pursue long-term development objectives. These complexities are explored in this paper. Although support for public participation in rural development is high, it is not universal. Cleaver (1999) highlights the lack of conclusive evidence showing that participation is an effective mechanism to improve the lives of society's most marginalised. In fact, the literature voices a number of critiques of both the concept and the operations of public participation. Buchy and Hoverman (2000) draw attention to the increased demands in terms of time and resources required for meaningful public participation. In the critique, the question of power is raised once again. Scholars note the tendency of certain groups (those that are organised, vocal, and informed, etc.) to overshadow others in the participation process (Buchy and Hoverman 2000; Cleaver 1999; Dasgupta and Beard 2007). Often the most marginalised groups are not represented due to various reasons, including lack of accessibility, poor transport, time constraints and lack of intellectual resources (Cleaver 1999), and even when the poor are present, their vulnerability to elite domination is high (Dasgupta and Beard 2007).

In South Africa, the rural development literature can be split into two camps: on the one hand, there are the supreme sceptics who argue that rural development since 1995 has been an unmitigated failure with several false starts because the 'real issues' of agrarian change have been ignored in favour of disjointed micro-projects (Cousins and Walker 2015; Hall 2015). On the other hand, there is a strong body of scholarship that insists 
on the importance of democratic agency in rural development programmes (Ntsebeza 2005; Du Toit 2018; Thompson, Tapscott, and Wet 2018). This article firmly positions itself with the latter scholarship and seeks to provide indicators of the positive role and potential of the CoS in the Rural Development Model.

\section{Methodology}

The research was conducted in three municipalities namely the City of Cape Town, Swellendam and Matzikama. The three research sites examined in this study were the City of Cape Town: Ward 29 (Atlantis, Mamre and Pella); Swellendam: Ward 3 (Suurbraak, Buffelsjag and Malgas/Infanta); and Matzikama: Ward 2 (Doornbaai, Papendorp, Lutzville West and Ebenhaezer). These sites, which are considered peri-urban and rural sites, are focus areas of the Western Cape Department of Agriculture. Matzikama has the largest land reform project in the Western Cape, with a coastal economy in addition to the other existing agriculturally focused activities. The CoCT (ward 29) on the other hand, offers a diverse set of three experiences: it is urbanised to areas of extreme informality and extreme poverty. The Swellendam municipality offers the opportunity to explore a rural area, Suurbraak, where the community has taken the rural development mission on in various ways that differs from what is seen in many other nodes because of many micro-projects.

The methodology included extensive interviewing of households in each of the selected wards (an average of 40 households per ward); key informant interviews with national, provincial and municipal officials and local office bearers (25 interviews in total); and interviews and focus group discussions with $\operatorname{CoS}$ members in each ward or node. Official interviews were done mostly telephonically and recorded. Focus groups sessions were also recorded took place at the three locations with an average of six CoS members per ward attending. All data gathering instruments were tested in a pilot phase before their use in the field. Due to the sensitivity of the issues discussed, individuals interviewed were assured of anonymity in their responses. This commitment is also adhered to in this article. For this reason, we use generic references in this article to substantiate our observations.

The data gathered was augmented by a review of various official documents, including documents from the National and Western Cape Governments, municipal Integrated Development Plans, and ISC meeting minutes. The analysis was based on a literature review of various aspects of the rural development dynamics both in the Western Cape and more broadly. We also drew on the literature on service delivery where community participation and choice was required as well as literature on actor networks, intergovernmental relations and departmentalism.

It is important to note that information generated through the interviews was based on the individuals' perceptions of the implementation of the Rural Development Programme in their locality. It was therefore not always possible to confirm the truth or accuracy of their claims. Nevertheless, through a process of triangulation in which different stakeholders were asked the same questions and reference was made to secondary published sources, it was possible to discern trends, which corroborated or dispelled the more contentious issues raised by the respondents.

Apart from the household interview, other data from the project lists, source documents such as meeting minutes and information from Statistics South Africa were also 
used for this article. The emphasis in these case studies is on the voices of the community as refracted in focus group meetings with the CoS. The community leaders had many insights and these were blended with observations from other sources and observations.

\section{The rural development model (RDM) in the Western Cape}

In response to the multiple challenges, and in giving effect to the mandate imposed by the CRDP, the Western Cape Government, through the Western Cape Department of Agriculture (WCDoA), developed its Rural Development Model (RDM) in 2010. With this model, the WCDoA aimed to tackle poverty, food insecurity, unemployment, the lack of basic services and to create 'a well-structured and organised community positioned to attract private investment' in selected nodes (WCDoA 2016). Consonant with the goals of the CRDP, the model sought 'meaningful community participation, leadership, and ownership in change efforts'. The RDM is designed as a phased approach aimed at mobilising communities at a rural ward level for the delivery of social services and the creation of opportunities for economic growth and job creation.

The Western Cape Government's RDM is derived from the CRDP which was formulated by the DRDLR. Although the CRDP proposed that provincial premiers should be the champions of the national programme (DRDLR 2009, 24), the responsibility for implementing the RDM has been devolved to the Western Cape Department of Agriculture (WCDoA) where it is located under its Programme 8 for Rural Development. The key policy priority of Programme 8 is to 'initiate, plan and monitor development in specific rural areas (CRDP sites) across the three spheres of government in order to address needs that have been identified' (WCDoA 2016)

A pilot RDM was implemented in Dysselsdorp, near Oudtshoorn, in 2010, and since then the model has been progressively rolled out. In its initial conceptualisation, it was intended that implementing the model in a selected node would extend over a period of three years, after which time, so it was anticipated, a measure of sustainability would have been achieved and government support could be reduced.

\section{Programme theory of change}

The theory behind the RDM is based on the setting up of an Intergovernmental Steering Committee (ISC), followed by a social facilitation process to constitute a CoS, the establishment of four workstreams combining government officials and community members, and the institutionalisation of a CoS. In terms of its original three-year sequential design, after the social facilitation phase, follows the social upliftment phase (skills and social projects), infrastructure development (roads, water, housing) and, finally, the economic development phase (take-off of businesses, co-operatives and job creation).

The central concern of this paper is the CoS which comprises representatives of all sectors in a community, including ward committee members. The $\mathrm{CoS}$ is a forum for engaging all spheres of government (hence promoting joined-up government or intergovernmentalism) to identify and prioritise potential development projects. High priority projects that are selected and approved by the CoS are referred to appropriate government departments for funding and implementation (WCDoA, Updated Version Rural Development Model, $\mathrm{n} d, 6)$. 
Each phase would be supported by a so-called work stream made up of relevant departments and community members linked to the CoS. It was hoped that the private sector would be more willing to invest in rural nodes once the phases were completed. The logic, in brief, was that 'a well-structured and organised community' would be 'positioned to attract private investment' in selected nodes (WCDoA 2016).

Functioning at a ward level, the approach is intended to be a bottom-up one with the community representatives providing input and approving projects to ensure that real community needs are articulated and acted upon. In the first stage, a detailed household profiling exercise is carried out in targeted rural development sites to ensure that government interventions are also based on accurate information and that poor households are targeted. This approach represents the model's 'theory of change'.

The establishment of the $\operatorname{CoS}$ as the authoritative representatives of communities makes assumptions. The first relates to the concept of community, which, as pointed out in the literature, it's difficult to define; means different things to different people in different contexts; is inherently unstable; and takes a long time to cohere (Bozzoli 1987; Thompson, Tapscott, and Wet 2018). Community expectations, protests, cultural and political conflict and the possibility that more powerful social groups may capture civic structures also pose higher risks, such as the fragmentation and de-legitimisation of CoS structures (Impact Economix 2015).

A second assumption in the RDM is that communities in poor wards are sufficiently heterogeneous to permit interest aggregation into discrete stakeholder groups at ward level. This raises a number of issues related to collective action problems (Booth and Cammack 2013). A third assumption is that combining a bottom-up (community leaders) and topdown (government officials) approach to rural development would proceed without difficulties in a relatively short time frame of three years. However, it is evident that for such a process to succeed, a considerably longer learning process is required and it is by no means guaranteed that conducting short training programmes for CoS will lead to compliance with the prescribed administrative processes.

The RDM assumes that conducive intergovernmental relations are necessary to ensure effective implementation of rural development exists. The recent Western Cape Provincial Government (WCPG 2014) asserts that delivery will not be successful without 'strategically aligned projects through enhanced project coordination, with project management, sequencing and scheduling to be better coordinated'. Rural development, it states, must be a 'truly intergovernmental effort' (WCPG 2014, 15-17). However, particular values including collaboration, integration, innovation, risk-taking and flexibility do not as yet exist in government, but need to be encouraged since there is a strong gaming instinct of bureaucratic performance where officials 'tick boxes'.

\section{Unpacking the council of stakeholders (CoS)}

The $\operatorname{CoS}$ has an executive committee and representatives from stakeholders in a rural area involving local sport bodies, religious and education institutions, businesses, co-operatives, women, CPA representatives, small-scale farmers, and the youth. These stakeholders were chosen at mass meetings and each area developed its unique configuration of stakeholders. It also includes representatives of various workstreams such as infrastructure, social facilitation 
and economic development programmes. Local ward councillors and social workers also attend. Members of the $\operatorname{CoS}$ are expected to draw up a constitution, open a bank account and function from offices that are made available by the local municipality.

The CoS interacts with local government (LG) on a formal basis in and through the Integrated Development Plan (IDP), local economic development (LED) and tourism and housing. The CoS projects are meant to be listed in the IDP as formal projects of local government. The CoS receives limited operating funds from the Western Cape Department of Agriculture (WCDoA), namely R100,000 per ward for three years. The CoS leadership are trained by the Cape Agency for Sustainable Integrated Development in Rural Areas (Casidra) and supported by rural development (RD) officials and the Department of Rural Development and Land Reform (DRLDR). Casidra is a WCDoA project management partner that assists in implementing the vision and goals of the CoS.

The Council of Stakeholders prioritises projects which are presented to ISC. The relevant government department or implementing agent will then be instructed to start with implementation. Thus the logic is to reinforce the idea that 'the people' must be served by government. The CRDP guidelines are that infrastructure development should be the first phase and economic development the last phase. An example would be providing water tanks so that local gardens could be more easily established, making it possible to serve possible local food markets in the future, and thereby creating local jobs. The main coordination aim of the ISC is to 'create a collective flow of resources to implement projects in the rural node to create socio-economic opportunities for the communities' (WCDoA 2016, 21).

\section{Thematically structured case studies}

Case studies of the operation of the CoS were done in the three wards. The major analytical crosscutting themes and criteria of success of the RDM were identified. These themes were: relationships between $\mathrm{CoS}$ and the community; with local government, with government departments and other stakeholders. These case studies are presented in three parts starting with Atlantis (ward 29). The recurring themes that emerge relate to relationship and trust by community organisations in the different levels of the state; activists willingness to serve the broader public interests at a significant cost to themselves; strong antipathy to DA dominated local government in the Western Cape; the nature of rural community participation and the design of inclusive community participation at the ward level and the political economy of small towns and rural areas.

Although the case studies are largely about organisational matters and therefore qualitative in nature, some quantitative data is presented derived from household interviews. We interviewed the head of the household. In the case of Suurbraak and Matzikama CoS, more direct quotes from stakeholders were used to convey the actors' point of view. The researchers could not verify what the respondents had told them, and thus, although there was a degree of triangulation and checking, this cannot be said to be exhaustive.

\section{City of Cape Town: ward 29 (Atlantis, Mamre and Pella)}

The apartheid government set up Atlantis in the late 1970s as a dormitory township for coloured people. Pella was established in the early 1800 s as part of a mission station. 
Over time some of this church-owned land has been incorporated into formal townships. Ward 29, a CRDP node in the City of Cape Town, comprises about half of Atlantis and the full extent of Mamre and Pella. Mamre and Pella are self-contained villages in their own right. Atlantis is split between Ward 29 and Ward 32. In 2011, the population of Ward 29 was 43,269, an increase of 28 per cent since 2001. The population is 94 per cent 'coloured' with Afrikaans being the most spoken language at home. The CoS members, government officials and heads of the households identified youth unemployment and the prevalence of alcohol and drug abuse as major social ills.

\section{Cos and the community}

The CoS was set up in 2011 and many organisations were invited to its initial meeting. In Pella, there were 16 and Mamre had 25 whilst Atlantis had 200 different organisations represented at the launch of the CoS. Two persons were selected to represent each organisation after which the CoS elected its own office bearers (Atlantis Focus Group Meeting 2016). At the start, there seemed to be great interests in all three areas, but soon separate CoS structures coalesced for each area.

Most households interviewed were aware of the presence of the CRDP and the CoS. They mentioned that these entities were not working that well. Whilst they expressed knowledge of meetings to discuss the CRDP, the respondents noted that meetings were poorly attended and erratic. From household interviews (see Table 1) it is evident that there was a high level of awareness of local politics, the CRDP, rural development and the CoS amongst the households that we visited. Households reported that they knew about the meetings to discuss development.

\section{Relationship with the local authority and ward committees}

Atlantis is meant to be is a major investment node for big industries. The Atlantis Revitalisation Framework, driven by national and city government presents a spatial framework according to which the development of Atlantis can be taken forward. The relationship between the CoS, the local authority and ward committees in Atlantis is complex. Firstly, the relationship between the ward committees, the ward councillor and the CRDP has caused some confusion. The ward councillor attended the ISC meetings but not the local CoS meetings. There are forces pulling the ward into large-scale spatial development plans.

\section{Relationship with other government departments/entities}

There were several informative presentations to the ISC from external partners and stakeholders who were interested in investing in the area. Whilst the initial meetings of the ISC

Table 1. Awareness of the RDM/CoS and development meetings.

\begin{tabular}{llccc}
\hline & Yes & No & Don't know & Total \\
\hline Have you heard of the CRDP/rural development programme? & 26 & 19 & 1 & 46 \\
Have you heard of the CoS? & 27 & 19 & 0 & 46 \\
Awareness of community meetings to discuss development & 37 & 7 & 2 & 46 \\
\hline
\end{tabular}


were well attended, they soon fell into lengthy needs assessments and wish list engagements. The CoS reported that were struggling to build stable relationships with government departments they had approached.

The department officials who attended the ISC and CoS meetings reported that for them these were frustrating engagements. Department officials had to engage in rural development processes, which had in their view no political, administrative, and budget-based allocations. They were more comfortable with working within municipal frameworks that were supported by existing government plans in the form of IDPs or provincial strategic planning frameworks. Government officials reported that they were already locked into much longer departmental planning and budgetary processes that did not fit well with the CoS (Interviews with Departmental officials 2016).

Yet, in the end, all the departments believed that they only had a facilitative role and could not and did not commit funding to the CRDP themselves. They blamed the failure of the process on not only the management of the meetings, but also the agendas and mandates of the meetings not being clear. They insisted that this was not an indictment of the provincial department of agriculture but a failure in designing the CRDP process and how the national department implemented it.

The responsibilities of the three levels of government did not cohere easily at ward level as envisaged by the CRDP. Instead, in this ward, the different levels of government (national, provincial and local) were pulling the process apart in the sense that they were driving their own agendas and operating in silos. It also did not help that political parties were reportedly seen to be looking after their own interests, which were often linked to political gains rather than community development (Atlantis Focus Group 2016). The ISC meetings' attendance registers were analysed and are presented in Table 2. The dates selected represent the first meeting, the last and a meeting midway for the period for which we had attendance registers.

As can be seen from Table 2, participation generally declined with fewer CoS members attending and a few government departments regularly attending the meetings. According to our interviews with WCDoA officials, the most consistent attendance was from the Department of Social Development, the Department of Health, Eskom, the City of Cape Town (CoCT), the Rural Development (National) and incubator hub agency. Pella's attendance was erratic, possibly because their representatives were at work.

As a crosscutting platform, the ISC struggled with getting departments and local authorities to commit to a comprehensive programme of rural development that prioritised the rural poor (Interview Chief Director, WCDoA).

There was also uncertainty in the provincial departments about the relationship that the provincial Department of Agriculture had with the National Department of Rural Development and Land Reform on the CRDP. This uncertainty resulted in the provincial

Table 2. Attendance at ISC meetings (Atlantis): 2015-2016.

\begin{tabular}{lccr}
\hline & ISC Meeting 1 & ISC Meeting 2 & ISC Meetings 3 \\
\hline Number of CoS attendees & 9 & 5 & 5 \\
Number of municipal officials & 2 & 0 & 2 \\
Number of provincial government department attendees & 15 & 15 & 12 \\
Others & 0 & 0 & 3 \\
Total & 26 & 20 & 22 \\
\hline
\end{tabular}


departments being unable to effectively champion rural development with a clear focus on improving the lives of the poor.

Yet it was recognised that information sharing about projects and plans between the departments was happening. This was seen by all as an important process attributed to the CRDP. The extent to which the process was able to raise the voices of those not previously heard was deemed a success by those who recognised the role of government in improving the lives of the poor in a manner that put people first. Ward 29 was the least coherent of all the three nodes and least successful in terms of the RDM criteria of success, although Pella and Mamre (and its Community Property Association) have achieved more community cohesion. The CoS was most active in Mamre, followed by Pella with Atlantis being the least active area. In Pella, the substantive work of the CoS revolved around resolving the land and housing problems associated with the churchowned land (https://www.news24.com/SouthAfrica/News/couple-to-receive-a-houseafter-50-years-in-a-shack-20170602).

\section{Swellendam: ward 3 (Suurbraak, Buffelsjag and Malgas/Infanta)}

Ward 3 consists of three geographically separated villages (Suurbraak, Buffelsjag and Malgas/Infanta), which are approximately 10 kilometres apart. Ward 3 has a population of 7800, spread over a wide area and with a density of five persons per square $\mathrm{km}$. Ward 3 makes up a significant 22 per cent of the total population falling under this municipality's jurisdiction (Stats South Africa 2016). In this ward, the average annual household income was reported to be R30,000 (about half the level of the province). Most of the economically active population work as farmworkers and in packing companies. Fewer than 6.4 per cent of households live in shacks (about a third of the rates of Western Cape).

Buffelsjag and Malgas/Infanta are more recent residential communities (established on private land acquired by Swellendam municipality) where the poor are mainly low-waged workers' on farms. These areas are characterised by severe social problems and concentrated poverty compared to Suurbraak. Suurbraak's inhabitants seemed to have more entrepreneurial tendencies than Buffelsjag.

\section{Relationship with the community}

Formed in 2014, the CoS had a small base in Buffelsjag and a bigger one in Suurbraak. The WCDoA officials called an information meeting using loudhailers in Suurbraak and Buffelsjag. Transport was provided for Buffelsjag since it is about 10 kilometres away. At this meeting attended by about 200 residents in Suurbraak community hall, government explained the CRDP and invited the community to form sector-based groups. Delegates were nominated to different sectors and an interim body established. But it had to be reconstituted after three members of the original CoS Suurbraak group resigned. The Cos had a good mix of older members and younger members with the latter and women being distinctly more optimistic and more oriented towards problem-solvingthan their older counterparts.

Table 3 indicates that although the majority of community members were aware of community meetings to discuss development, many were not aware of the CRDP or the CoS. The structured relationship with the community (through AGMs, report backs, etc.) 
seemed to have broken down. CoS members further noted that there was a long history of community cynicism in Suurbraak: 'There are too many promises made to people of Suurbraak'. Community awareness of the CRDP might have been at a high point in 2014 when public meetings were held. High-profile government officials visited the area and members of the Department of Social Development and the National Rural Youth Service Corps (NARYSEC) conducted interviews with households.

\section{Relationship with the local authority and ward committees}

There were mixed opinions among CoS members about the Swellendam Municipality (a DA majority town). The CoS chairperson and vice-chairperson regarded the Swellendam Municipality as somewhat positive even if adversarial. Several other CoS members, however strongly criticised the municipality:

There are so many opportunities coming via the municipality, but they don't bring it to us. We get information but they are gate-keeping and blocking opportunities.

The majority of the CoS were more hostile towards the Swellendam Municipality:

They [Swellendam Municipality] don't budget for the three wards because they know it's a rural ward. In this municipality the municipality only spends money on the rich people.

The focus group also complained about the Swellendam Municipality's actions in claiming that they had initiated successful projects, whereas these were CoS projects:

[They] hijacked the community hall project. When rural development (department) found out they nearly withdrew. The municipality takes the CRDP as its chance to lengthen their arms. The Swellendam [Municipality] did nothing to help. Swellendam is getting the brag from us and taking advantage of a national programme.

The words 'hijack' and 'claiming credit for CoS's work' emerged as strong themes among CoS members. The example of the World Food day was cited. There was considerable cynicism towards the ward councillor seen as unwilling to champion Ward 3 causes. CoS members articulating their feeling that Swellendam was a large town sucking out the spending power of Suurbrak and Buffelsjag and 'not put anything back'. The CoS, therefore, highlighted the uneven nature of development across the municipality.

\section{Relationship with other government departments/entities and with political parties}

The uneven attendance of the ISC meetings by CoS members is reflected in Table 4. In contrast, other government departments were well represented.

A key CoS official said: 'I have a relationship with national and sometimes national is ahead of municipalities and provinces. National is a gatekeeper and province is left out

Table 3. Awareness of CRDP and CoS development meetings.

\begin{tabular}{lcccc}
\hline & Yes & No & Don't know & Total \\
\hline Have you heard of the CRDP? & 8 & 33 & 0 & 41 \\
Have you heard of the CoS? & 10 & 31 & 0 & 41 \\
Awareness of community meetings to discuss development & 24 & 17 & 0 & 41 \\
\hline
\end{tabular}


sometimes. I also represent women in Overberg'. We (as chair and vice-chair) meet every three months now and we meet SEDA, transport and education (ABET).

But as some key state informants argued (Interviews, government officials), rapidly changes policy directives and programmes (co-ops, agri-parks and 'one home one acre') meant that officials themselves found it hard to keep up with rapid policy and programme change. The Breede-Overberg Catchment Management Agency (Bocma) seen as the most responsive because they were responsible for the water tanks.

In terms of actual service delivery there was much to celebrate and to criticise:

Buffelsjag has electricity and gardens ... but we got a piece of land with no fence and water pump and our dirt is not removed. At Suurbraak there is cooperative for piggery farms ... but two years later we still have to cart water with our cars and the municipality does nothing. Rural development has money but the official do not want to help us. (Suurbraak Focus Group 2016)

Buffelsjag received land but no fencing and the agricultural extension officer refused to help them.

The Department of Basic Education paid for scholars' transport, which was seen as a victory. But the CoS members listed a number of projects that had received little or no help from the municipality. Some of these projects included 'Piggeries, Woolworths goats milk, and Nguni cows'. CoS members pointed to achievements but with a certain degree of bitterness because they had to personally fund the CoS.

A major activity of $\operatorname{CoS}$ was initiating a number of training projects for youth through FET (computer training, leadership) and a Department of Transport scheme to assist 120 youth to get learners licenses. CoS members felt that training was good but one member stressed 'where do young people go after training except to Swellendam or further' (Focus Group Interviews 2016). As part of the CoS's duties, important partnerships have been developed: 'We have four business registered in Suurbrak and one registered with the Small Enterprise Development Agency. A number of small agricultural projects such as berries and essential oils are being set up with local women and private white farmers and/or investors. Some of these products are earmarked for established export markets. The mentorships are still in process' (focus groups and interviews). All CoS members argued that the church was a major role player and that religion had divided Suurbraak in the past: 'the relationship between churches and $\operatorname{CoS}$ was good because we announced events in churches'.

\section{Matzikama: ward 2 (Doringbaai, Lutzville West, Papendorp and Ebenhaezer)}

Ward 2 in Matzikama (West Coast) consists of four areas (Doringbaai, Papendorp, Ebenhaezer and Lutzville West) with a population of 8400 . Only 2 per cent of households live in

Table 4. Attendance of Swellendam ISC meetings: 2014-2015.

\begin{tabular}{lccr}
\hline Date of meeting & $5 / 12 / 2014$ & $25 / 2 / 2015$ & $18 / 11 / 2015$ \\
\hline Number of CoS attendees & 3 & 5 & 2 \\
Number of Swellendam Municipality attendees & 6 & 2 & 4 \\
Number of government department attendees & 15 & 14 & 13 \\
Others & & 2 & 2 \\
\hline
\end{tabular}


shacks compared to 18 per cent in the entire West Coast (RSA 2011). About 61 per cent of registered voters cast their votes in the 2016 municipal elections with 51 per cent voting for the Democratic Alliance (DA) and 42 per cent for the African National Congress (IEC, Municipal Elections 2016). The majority of the population are coloured (90\%) and Afrikaans-speaking (75\%). These areas are about 10 kilometres apart and the four areas were all represented in the CoS.

The RDM started in 2011 and by March 2016 there were a number of infrastructure upgrades and new infrastructure projects, training and social projects. Some projects were completed (such as oxidation ponds, vegetable gardens and paving projects) whereas others have been difficult (such as a sports field, and aquaculture and abalone projects). Despite the negative perceptions, several major successful completed projects were applauded by the CsS (Reservoir R3 million and Oxidation Ponds R5.7 million). It was reported that plans for Ebenhaeser Irrigation had been approved and R80 million set aside. This confirmed the view of a key COS member who spoke of the 'sweet and sour of rural development'. The ward is particularly interesting because of the intervillage dynamics and power issues between the municipality and the $\mathrm{CoS}$ village structures.

\section{Relationship with the community}

As can be seen from Table 5, there was a high level of awareness of meetings to discuss development but knowledge of the CRDP and the CoS was limited.

The CoS had an intimate relationship with the local community at a village level. Leaders had the maturity to handle inevitable debates and arguments among community members.

There [are] always people who are positive and negative.... We had community meetings to discuss how to spend the R10 m project for fish farming. The community was involved in the discussions but the municipality created major problems with the CoS. Now the community lost faith in us.

The focus group had very interesting observations:

The CoS has a life cycle: you get a noisy people in meetings and then real work that is needed. The big question is whether a community sector should be more of a driver than a CoS. If a sector can be effective on its own, then why have a CoS. In Ebenhaezer the CPA, which is better, organised than the $\operatorname{CoS}$ and most people rather go to CPA for assistance.

Relationship with the local authority and ward committees

The relationship with local government was reported to be 'most difficult since municipal officials largely work against us. He ward council does not operate and very poorly attended'. Members added:

Table 5. Awareness of CRDP and CoS development meetings.

\begin{tabular}{lcccc}
\hline & Yes & No & Don't know & total \\
\hline Have you heard of the CRDP? & 19 & 14 & 1 & 34 \\
Have you heard of the CoS? & 19 & 15 & 0 & 34 \\
Awareness of community meetings to discuss development & 23 & 11 & 0 & 34 \\
\hline
\end{tabular}


The IDP, which happens every five years, is used against CoS. The municipality does not understand the importance of CoS. People need to understand the role of CoS. It is above that of a ward committee. We are told that we are a higher structure linked to national and province. We struggle with this because people go the CPA and not the CoS. The main advantage for the $\mathrm{CoS}$ is that we get national attention for our communities and projects do happen. But local government must support us. (Matzikama, Focus Group 2016)

Relationships with other government departments/entities and the ISC

As shown in Table 6, the vast majority of participants were from government departments, while the attendance of $\operatorname{CoS}$ members was also good.

The CoS has had a good relationship with national government:

They understand the needs of the community. But they play the political game. We all know the Western Cape is DA-governed. National government does not want to give money to the Western Cape. That is why we want money to be filtered directly through the CoS to the community.

Often government comes with a project and expects CoS to endorse it: 'At times we are shocked with this'.

But relations with province (ISC) is complicated. They don't send senior people; decisionmakers are not at ISC. Municipal officials attend the ISC. The Western Cape has issues such as ANC versus DA with national and politics overrides development and technical issues. (Matzikama Focus Group 2016)

The CPA is a major player in this ward. Youth, women and anti-drug abuse committees have been established. CoS has not met organised business: 'we have Top Crop, a big organisation of white farmers that can be engaged. Mining and fishing companies have also been engaged outside of the ISC' (Matzikama Focus Group 2016).

There was a very positive feeling that the $\operatorname{CoS}$ was worthwhile and government was more responsive. As one community activist in $\operatorname{CoS}$ noted;

CoS gives us traction and clout with national government. We have a lot of authority since we are expected to approve all projects in our area. We need to be informed of any developments. Every three months government work streams see us. CoS is effective because we can get government to listen. (Interview with CoS member 2016)

\section{Conclusion}

Most existing studies on the CRDP and the Western Cape's Rural Development Model (RDM) are thin on detailed knowledge of participation processes at a local level and they tend to devalue the CRDP, describing it as an ill-conceived and failed intervention. Yet, it is the only programme that attempts to be truly intergovernmental and that is driven in part by communities from below through an innovative overarching structure - the Councils of Stakeholders. On balance, we found the CoS to be an important for processes of community mobilisation, airing grievances and community

Table 6. Attendance of Matzikama ISC meetings.

\begin{tabular}{lcrr}
\hline Date of meeting & $2 / 5 / 13$ & $12 / 11 / 14$ & $21 / 10 / 15$ \\
\hline Number of CoS attendees & 7 & 11 & 10 \\
Number of Matzikama Municipality attendees & 3 & 2 & 3 \\
Number of government department attendees & 20 & 21 & 17 \\
Other & & & 1 \\
\hline
\end{tabular}


empowerment and learning. The primary success of the RDM was that these processes provided unprecedented opportunities for community leaders to become more educated about and engaged in development issues. Moreover, it afforded community activists unmatched opportunities to directly interact with the government as a whole. Almost all CoS members appreciated the learning process and as one member said, 'because of CoS we learn something new every day' (Matzikama, Cos Focus Group 2016). Political and project knowledge became more generalised; citizen-leaders became vastly more educated about the inner workings and potential of a developmental state.

Moreover, community activists have first-hand and immediate encounters with state officials. The perception of the state as a hidebound, intrinsically hostile, impenetrable bureaucracy was reduced and activists could open lines of communication with state officials at all levels. They differentiated between allies in the state. The 'us-versusthem' concept, where communities see themselves as radically separate from the state was reduced. A new space for collective action towards solving problems emerged. People felt that they were also equal to the state - after all, the people own the state.

Participation despite its vagaries should be seen as a worthy end in itself and of immense public value (Irvin and Stansbury 2004). The study shows that for community empowerment to succeed, a considerably longer learning process over a longer period than three years is required.

In sum, our findings show that CRDP elevated the agency of local leaders significantly and that these deep processes of building community collective agency and local leadership provide an invaluable platform for future engagement on the land question. On the opposite side, an unintended consequence was that government officials became very knowledgeable about the challenges in communities and also more aware of the internal weaknesses of the ways the state was organised and the challenges of getting various spheres of the state to work together. The CRDP after all, was premised on some form of joined-up government yet operates on a performance management and financial accountability system that is departmentalised.

\section{Acknowledgements}

We would like to thank Mr Mohamad Motala, Ms Toni Xaba, Professor Christopher Tapcott, Dr Leon Pretorius and the post-graduate students who assisted in collecting the data as well as officials who gave of their time for interviews. The authors wish to thank the Western Cape Department of Agriculture for supporting this research.

\section{Disclosure statement}

No potential conflict of interest was reported by the authors.

\section{References}

Agossou, V., and W. S. Ayres. 2000. Village Participation in Rural Development: The African Network on Participatory Approaches.

Booth, D., and D. Cammack. 2013. Governance for Development in Africa Solving Collective Action Problems. London: Zed Press. 
Bozzoli, B. 1987. Class, Community, and Conflict: South African Perspectives. Johannesburg: Ravan Press.

Buchy, M., and S. Hoverman. 2000. "Understanding Public Participation in Forest Planning: A Review." Forest Policy and Economics 1 (1): 15-25.

Cleaver, F. 1999. "Paradoxes of Participation: Questioning Participatory Approaches to Development." Journal of International Development 11 (4): 597.

Cousins, B. 2016. Land Reform in South Africa is Sinking. Can it be Saved. Belville: University of Western Cape: PLAAS.

Cousins, B., and C. Walker, eds. 2015. Land Divided, Land Restored: Land Reform in South Africa for the 21st Century. Johannesburg: Jacana.

Dasgupta, A., and V. A. Beard. 2007. "Community Driven Development, Collective Action and Elite Capture in Indonesia." Development and Change 38 (2): 229-249.

Du Toit, Andries. 2018. "Without the Blanket of the Land: Agrarian Change and Biopolitics in PostApartheid South Africa." The Journal of Peasant Studies 45 (5-6): 1086-1107.

Francis, P., and R. James. 2003. "Balancing Rural Poverty Reduction and Citizen Participation: The Contradictions of Uganda's Decentralization Program." World Development 31 (2): 325-337.

Hall, R. 2015. "Mapping ANC Policy Development on Land and Agrarian Reform Since 1994." In Land Divided, Land Restored, edited by B. Cousins and C. Walker, 276-289. Johannesburg: Jacana.

Hall, R. 2019. "Farm flipping: how land reform was broken by the elite." Mail and Guardian, May 24.

Impact Economix. 2015. Implementation Evaluation of the CRDP In Dysselsdorp: Final Report: (Impact Economix: WCDoA).

Irvin, R. A., and J. Stansbury. 2004. "Citizen Participation in Decision Making: Is it Worth the Effort?" Public Administration Review 64 (1): 55-65.

Kakumba, U. 2010. "Local Government Citizen Participation and Rural Development: Reflections on Uganda's Decentralization System." International Review of Administrative Sciences 76 (1): 171-186.

Statistics South Africa. 2016. Municipal Elections 2016. Available online: https://www.elections.org.za/ content/Elections/Downloadable-results/Detailed-results-data-2016-Municipal-Elections/.

Tapscott, C. 2017. Personal Interview. 16 November.

Thompson, L., C. Tapscott, and P. T. D. Wet. 2018. "An Exploration of the Concept of Community and its Impact on Participatory Governance Policy and Service Delivery in Poor Areas of Cape Town, South Africa." Politikon 45 (2): 276-290.

WCDoA. 2011. Rural Nodal Development Model. Elsenberg: Western Cape Provincial Government.

WCDoA. 2016. Briefing Document Rural Development Model Evaluation. Elsenberg: Western Cape Provincial Government.

WCPG. 2014. Western Cape Provincial Government Strategic Plan 2014-2020. Cape Town: Western Cape Provincial Government.

WC Rural Development Model updated. n.d. Western Cape Department of Agriculture: Elsenberg. Interviews and Focus groups

Interview. 2016. Senior Manager in the Department of Agriculture August 2016 Evaluation of the Comprehensive Rural Development Programme.

Interview. 2016. Municipal official, Suurbrak municipality August 2016 Evaluation of the Comprehensive Rural Development Programme.

Interview. 2016. Provincial Government Manager - Department of Rural Development and Land Reform; August 2016 Evaluation of the Comprehensive Rural Development Programme.

Focus Groups No.1 Suurbrak CoS. July 2016.

Focus Group No. 2 Matzikama CoS. July 2016.

Focus Group No. 3 Mamre CoS. July 2016. 